\title{
La valoración de los fondos antiguos en bibliotecas
}

The assessment of old book collections in libraries

\begin{abstract}
Manuel José PedRAZA GRACIA
Universidad de Zaragoza, Departamento de Ciencias de la Documentación e Historia de la Ciencia, Pedro Cerbuna, 12, 50009 Zaragoza, pedraza@unizar.es
\end{abstract}

\begin{abstract}
Resumen
Las bibliotecas con documentos antiguos potencian la valoración de sus fondos mediante la investigación. Se recomienda la puesta en valor de los fondos mediante la difusión de los contenidos y de sus circunstancias por Internet, sin olvidar los sistemas clásicos de la difusión para la recuperación. En este sentido y especialmente, la confección de facsímiles y las exposiciones son capitales para la puesta en valor de los fondos.
\end{abstract}

Palabras clave: Colecciones antiguas. Valoración. Libro antiguo. Bibliotecas. Investigación. Exposiciones. Facsímiles. Accesibilidad. Difusión.

\section{Introducción}

El conjunto de los libros antiguos que posee una biblioteca suele recibir el nombre de fondo antiguo, que lo diferencia, sin lugar a dudas, del resto de la colección de la biblioteca, término, perfectamente definido por Manuel Carrión (1987, p. 60-61). Esta denominación es algo más restrictiva que el término patrimonio bibliográfico utilizado en otros países para designar el conjunto de los manuscritos y de las publicaciones antiguas existentes en una biblioteca determinada, y convive con otras más o menos descriptivas con influencias diversas: fondos antiguos y valiosos (Bibliotecas del CSIC), fondo reservado (Nacional de México), incunables y libros raros y curiosos (Nacional de Colombia), libros antiguos (Nacional de El Salvador), libros antiguos, raros y curiosos (Nacional de Bolivia), manoscritti e rari (Biblioteca Nazionale Centrale di Roma e Nazionale di Napoli), manuscritos, incunables y raros (Biblioteca $\mathrm{Na}$ cional de Madrid), reserva o reservados (bibliotecas nacionales de París o Lisboa), raros y curiosos (Nacional de Cuba), raros y notables (Histórica Municipal de Madrid), tesoro (Biblioteca del Palacio Real de Madrid), fondo conventual (muchas bibliotecas mexicanas), rare book and special collections division (Library of Congress)...

\begin{abstract}
Old book collections can get more valuable by research, Intenet publishing and traditional dissemination systems, like facsimiles and exhibitions.
\end{abstract}

Keywords: Ancient collections. Valuation. Ancient books. Libraries. Research. Exhibitions. Facsimile.

\section{El fondo antiguo}

En las bibliotecas de tamaño mediano y pequeño, las colecciones y fondos compuestos por libros y otros documentos antiguos, constituidos a lo largo de la historia de cada una de las respectivas instituciones, en muchas ocasiones, corren el riesgo de ser considerados como elementos incómodos dentro del conjunto general. Se relegan con frecuencia a una difusión escasa o inexistente, debido a cierto desconocimiento de la misma y a la carencia de personal para atender estas colecciones, y se busca que exijan la menor inversión posible en todos los sentidos: de personal, económica..., debido a que estos fondos, tomados de forma individual, presentan un bajo índice de préstamo. Se produce un conflicto entre la aplicación de criterios no aplicables (los libros antiguos son distintos y poseen valores distintos que los modernos) y se olvida su función patrimonial. De esta manera, se transforman en compartimentos estancos, tanto a los efectos de crecimiento o evolución, como también a los efectos de valoración. Tampoco es extraño a esta presunción el hecho de que para la sociedad actual lo antiguo, lejos de ofrecer la base sobre la que se sustenta lo actual está siendo considerado como carente de interés. 
Muchas bibliotecas consideran su fondo antiguo como algo que está, que no requiere especial dedicación, salvo cuando se trata de su preservación o de su consulta.

El material antiguo, adquiere en estos casos diversas connotaciones. En unos casos, se suele considerar como la riqueza latente de la biblioteca, se preserva de cualquier peligro, se muestra a los visitantes importantes y se usa con el máximo cuidado posible, pero no es preciso enriquecerlo ni aumentarlo, es el que es, y ya es bastante problema. En otros, es un material no deseado, está ahí y no interesa a nadie. Cuando alguien lo solicita lo consulta en una sala especial multiuso, requiere una dedicación para su conservación y, por tanto, decaer fondos imprescindibles para el buen funcionamiento de la biblioteca. $Y$, en otras, es el objeto único o preferente de la biblioteca, una biblioteca a la que se califica de histórica y que tiene características específicas... La propia legislación vigente no entiende que sea objetivo prioritario el incremento del Patrimonio cuando en su preámbulo indica la Ley de Patrimonio Histórico Español: “...como objetivo último, la Ley no busca sino el acceso a los bienes que constituyen nuestro Patrimonio Histórico..."

Pero, hay muchas bibliotecas que poseen un rico legado bibliográfico procedente de los diversos avatares por los que ha transcurrido su historia: su evolución lógica, las donaciones de sus miembros, expropiaciones o desamortizaciones, la inversión de la propia entidad, la voluntad política, entre otras. Las normativas tomaron en consideración muy pronto que el fondo antiguo requería un tratamiento diferente del que se llevaba a cabo con el resto de los materiales de la biblioteca, lo que indica que los profesionales de las bibliotecas responsables de la redacción de las primeras normativas fueron conscientes muy temprano de que debían diferenciar los materiales antiguos y los modernos, también por lo que hacía a su tratamiento. En la actualidad, existe una normativa específica para el tratamiento de los materiales antiguos que queda perfectamente encuadrada dentro de las reglas generales de descripción y aún de catalogación, pero no por esto dejan de requerir un tratamiento específico que precisa un cierto conocimiento de los mismos. Éstos no pueden circunscribirse exclusivamente al libro impreso o manuscrito, hay también materiales cartográficos, estampas, dibujos, obras musicales que debido a las características impuestas por el momento en el que fueron fabricados requieren el mismo tratamiento especial y que conforman también el fondo antiguo. En estas bibliotecas son diversos los esfuerzos que se deben hacer para la preservación de un fondo compuesto por un conjunto de ejemplares que son siempre escasos y, en ocasiones, únicos. La actuación es doble evitar el daño al libro preservándolo de los agentes que puedan atacarlo y, cuando el desperfecto se ha producido, repararlo. También la difusión y circulación, en muchas ocasiones, están sujetas a normas específicas con objeto de favorecer la protección del fondo antiguo, y, además, han de llevarse a cabo esfuerzos para difundir sus fondos antiguos.

Mercedes Dexeus (2001, p. 15) ha definido la actividad de estas bibliotecas:

Las instituciones públicas españolas suelen adquirir, cada una de acuerdo con sus propios fines, los libros y los documentos de interés histórico, que aparecen en venta en España y en el extranjero. Con ello, cumplen su misión de reunir, conservar y difundir el patrimonio cultural del país; evitan, en ciertos casos, la pérdida o desvalorización de los testimonios históricos que custodian, debidas al deterioro de ciertos ejemplares, y colaboran en el enriquecimiento del patrimonio bibliográfico y documental del estado, la región o el municipio, para su utilización y disfrute por los ciudadanos.

De esta manera, Dexeus aporta una definición de las funciones de las bibliotecas a la hora de relacionarse con su fondo antiguo y especialmente de los cometidos que cumplen las bibliotecas cuando adquieren fondo antiguo.

En los últimos tiempos se están desarrollando con mucho éxito un conjunto de centros bibliotecarios dedicados con exclusividad a los fondos antiguos de las instituciones, las denominadas bibliotecas históricas, que con su desarrollo están ofreciendo procedimientos y vías de actuación para la valoración de sus propios fondos antiguos.

\section{Los valores del libro antiguo}

Pero, ¿qué características posee este fondo antiguo? El fondo antiguo se constituye como un elemento que determina (no siempre) su propio interés mediante los grandes rasgos definidos por sus propias características. Los libros (especialmente los antiguos) tienen una historia que deja huellas en ellos, derivada de la actuación de la autoridad, de los avatares lógicos de la propia producción, de su comercialización, de la voluntad de sus propietarios... dando lugar a determinadas particularides, tales como: la presencia de ex-libris, sellos, notas y apuntes, correcciones, encuadernaciones, guillotinado de márgenes, iluminación de ilustraciones, intercalación de hojas en blanco, mutilaciones, restos del ataque de insectos, oxidación del papel, censuras, banderillas, etc. Es, por tanto, verdaderamente difícil hallar dos ejemplares idénticos 
de una obra, y, tanto más, cuanto más antigua sea su fecha de producción, ya que objetivamente más ha podido actuar sobre ellos la actividad humana, física, biológica, etc. A las instituciones, como a los bibliófilos, les interesa especialmente el valor o el conjunto de valores que atesora cada ejemplar concreto. No obstante, existen diferencias en la apreciación de estos valores que se fundamentan en dos direcciones distintas, mientras que el bibliófilo toma como fundamento su propia apreciación del valor o de los valores del ejemplar, el bibliotecario no puede dejar de tomar en cuenta un conjunto de factores objetivos que en muchas ocasiones lo individualizan de cualquier otro ejemplar de la misma edición.

Las obras tienen que ver - no podría ser de otra manera- con la biblioteca, o mejor, con el fin de la biblioteca. El interés de la biblioteca suele ser el resultado de la producción bibliográfica o de las aportaciones científicas y literarias realizadas por los naturales de un ámbito geográfico concreto, o por el contenido de las obras. Pero, siempre han quedado definidos mediante rasgos generales, ya que resulta imposible descender a la unidad. Una colección, cualquier colección, es el resultado de la actividad bibliotecaria cotidiana de una biblioteca, tanto si pertenece a una institución como a un individuo. Esta afirmación condicionada por la existencia del transcurso del tiempo determina que un fondo bibliográfico antiguo sea la mayoría de las veces el resultado de la fosilización de una colección.

Desde esta perspectiva, cada libro poseyó en su momento y posee en la actualidad un valor o unos valores propios determinados por diversos factores que pueden ser tanto intrínsecos como extrínsecos.

En primer lugar, el autor y la obra son determinantes como elemento principal de valoración, muy especialmente entre los manuscritos. La condición de inédito de un manuscrito es trascendente en su valoración si bien está matizada por la importancia del autor. Nuevos valores propios de los manuscritos son la condición de original (frente a la de copia), en ese caso, la de autógrafo, y en éste la de la inclusión de una firma (siempre habrá de cuidarse con las falsificaciones). Pero el valor del autor o de la obra no puede establecerse en su relación con su importancia histórica, científica o cultural... ya que estos no son los únicos valores que pueden afectar al libro. La composición material influye en muy menor medida, prácticamente sólo en los códices medievales. Precisamente en este tipo de libros, los manuscritos, la identificación de la copia de la que se trata y de su relación con otras, mediante comparación, es también definitiva por lo que respecta al establecimiento de la sucesión de los textos y de la determinación de la relación del ejemplar con el original primero de la obra, esto es, el grado de relación del autor con el manuscrito que posee la biblioteca. Se trata, en definitiva, de determinar, la fecha y lugar de ejecución y, a partir de estas, las circunstancias que lo acercan o alejan del autor. Excepcionalmente, su valor artístico puede ser muy evidente y concluir como elemento relevante para su valoración sobre cualquier otro parámetro.

La edición de la obra será factor determinante en la valoración de ejemplares impresos, la tipografía, el soporte, las ilustraciones, en suma, la estructura material, será el auxiliar de mayor trascendencia para su posterior identificación. También se puede valorar una obra por pertenecer a una determinada variante. No se debe olvidar que el libro antiguo es el producto de una labor más artesanal que industrial, esta particularidad consustancial al objeto dificulta la identificación de los datos que proporcionarían una descripción de un "ejemplar ideal," que sería el objetivo principal de tratamiento en la normativa. Pero los conceptos 'artesanal' y 'normalización' no parecen fácilmente conjugables. Ser el resultado de una actuación artesanal dota al libro antiguo de valores que no se pueden apreciar en el libro moderno.

Pero, además, hay otros múltiples factores bien alejados de los que pueden incidir en el libro moderno. Se valora una obra por su encuadernación (valor artístico o histórico...), por su exlibris (interés en la reconstrucción de las obras que pertenecieron a un determinado poseedor o por el valor artístico del propio ex-libris...), por sus ilustraciones (por la procedencia del autor, el valor artístico...), por la intervención explícita del autor en el ejemplar (autógrafos, dedicatorias...), por la intervención de la censura (valor histórico o sociológico), por los testimonios de lectura (valor científico, literario o histórico...) aspectos, éstos, que raramente se pueden considerar en el libro moderno.

De esta manera, se puede llegar a situaciones en las que interesa fundamentalmente la encuadernación, el autógrafo, la anotación, la ilustración o el ex-libris de un ejemplar, pero el contenido tiene un interés muy menor, o viceversa una obra muy interesante incrementa su(s) valor(es) por la presencia de encuadernaciones, autógrafos, o ex-libris verdaderamente notables que resultan en ocasiones indiferentes a los intereses de la biblioteca. En cualquiera de los casos también estos factores inciden en el(los) 
valor(es) del fondo antiguo de la biblioteca. Julián Martín Abad (2004) dice al respecto:

[...] el bibliotecario de fondo antiguo toma siempre en consideración la colección en la que dicha pieza quedará engastada, teniendo siempre en mente que esa colección está abierta al estudioso o al público en general, que cubre las necesidades de investigación, de información o de docencia de una colectividad.

También es preciso que las obras se ajusten a unos determinados estándares de conservación (se omite cualquier mención a la ausencia de integridad del ejemplar que lo invalida para su valoración, salvo que sean los únicos restos conocidos conservados de la edición o un manuscrito, o uno de los escasos ejemplares impresos conocidos). Precisamente, este parámetro obliga a que la biblioteca deba tener identificadas sus propias obras mútilas o incompletas, aunque no lo parezcan porque se hayan completado en el pasado o porque sean susceptibles de ser completadas. Tampoco deben confundirse con obras restauradas, que, a los efectos de los valores del libro, para una biblioteca no tienen demasiada trascendencia. La revisión con cierto detenimiento de las obras para evitar que obras completadas (pero mútilas) pasen por obras íntegras es un precepto imprescindible. Como ha planteado Carlos Clavería (2002):

[...] un responsable del patrimonio público ha de saber que el precio del documento que custodia es incalculable si es único, pero que literariamente se puede suplir con una buena copia: aprendamos para eso de la visión de futuro de los copistas humanistas del siglo XIV. Se podría añadir junto a precio (y el valor o valores) sin estridencia alguna, ya que el precio es lo que se da y el valor es lo que se recibe y son, solamente en esta perspectiva, semejantes.

\section{El tratamiento documental como primera valoración}

En la biblioteca la identificación y la individualización del documento antiguo son dobles y verdaderamente capitales, ya que no sólo se trata de identificar la obra del resto de las del fondo antiguo de la biblioteca e individualizarla para su posterior localización, sino que se pretende también identificar el ejemplar como perteneciente a una determinada tirada de la obra, en primer lugar, e individualizarlo del resto de los ejemplares de la misma mediante las características propias adquiridas en el transcurso de su historia bibliográfica, subsecuentemente.

El libro antiguo, como material especial que requiere un adecuado tratamiento para su conservación, presenta una característica añadida: el de su accesibilidad o disponibilidad para la consulta. La legislación del Patrimonio no solo se centra en su defensa, sino que garantiza el acceso al investigador. El acceso al fondo antiguo es una obligación que satisface una necesidad. Obligación, puesto que la legislación deja muy claro que, junto a la conservación, el sentido último de todas las actuaciones con dichos fondos es garantizar su acceso al usuario. Necesidad, porque los investigadores precisan la consulta de estos libros, que, como depositarios del conocimiento, son estudiados tanto desde el punto de vista intelectual como también material.

El tratamiento del libro antiguo, a diferencia del libro moderno, exige siempre un proceso de investigación. Cuando se trata un libro antiguo o moderno, se busca proporcionar una representación de un ejemplar estándar de una edición. Esta actuación no representa ningún problema con los libros modernos, ya que los datos que aporta el propio documento sirven de manera intuitiva para diferenciarlo de otras ediciones; sin embargo, puede ser muy problemático con ejemplares antiguos que han sufrido actuaciones de todo tipo durante su historia. El tratamiento del libro antiguo exige un proceso previo a la catalogación que se denomina identificación. La identificación de un objeto con tantas facetas y aspectos no puede producirse sin cierta complejidad.

El tratamiento del documento, su análisis documental, se inicia - cuando de libros antiguos se trata- con la labor de identificación, que exige dos fuentes: el propio documento, que ofrece la información de referencia para la identificación; $y$, como segunda fuente, las herramientas de identificación que aportan la información imprescindible para la correcta identificación del documento estableciendo el ejemplar ideal de la edición a la que pertenece y la condición de ejemplar manipulado (si lo ha sido). Sólo en ese momento se inicia el tratamiento que se lleva a efecto sobre el denominado ejemplar ideal.

La precisión de una identificación previa, que puede parecer obvia, se sustenta en la exigencia de la identificación de todos los aspectos que afectan al manuscrito e impreso antiguo dando lugar a distintos niveles de identificación, que pueden dividirse en tres estados: a) identificación del grado de integridad documental; b) identificación sustancial, característica y singular; y c) identificación formal y material.

La identificación (o la suma de las identificaciones) se articula como una parte sustancial de los procesos de valoración y tasación resultando ser el primero de los pasos y el determinante en la corrección de estos procesos. Los errores 
identificativos se transfieren siempre al resultado final, ya que interfieren en el exacto conocimiento del objeto que se tiene delante y, consecuentemente, este déficit se trasfiere a la evaluación del objeto y de ahí al resultado.

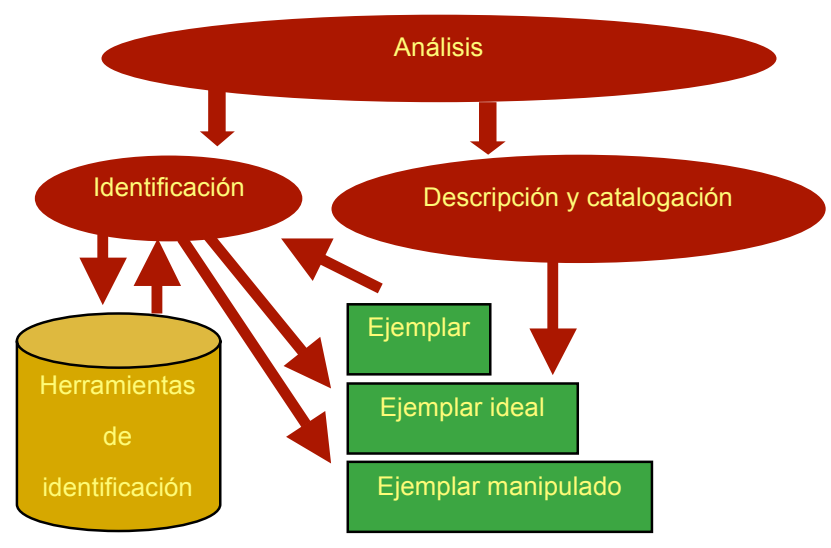

Figura 1. Situación de la identificación en el tratamiento documental

En este proceso, se procede investigar la integridad del documento. Las revisiones de la integridad del libro requieren un ojo educado a la vista de obras antiguas y de sus características con objeto de identificar las restituciones, ya que estas suelen estar muy bien hechas y pueden pasar completamente inadvertidas a ojos inexpertos. No se debe olvidar que no se trata de obras falsas, sino de obras que han podido ser mutiladas en tiempos pasados y reconstruidas en tiempos más o menos próximos a los actuales.

En un segundo paso, se procede a la identificación sustancial y característica, que tienen como objetivo identificar la obra, el autor y la materia, la primera de ellas, y los responsables de la edición y la edición y variante correspondiente, la segunda. La ausencia de datos es crónica en algunos tipos de documentos. La ausencia de datos sobre el taller que produce el libro es también frecuente, hasta el extremo que la legislación contemporánea entra con frecuencia en el tema a los efectos de control.

Por tanto, en el proceso de tratamiento del libro antiguo se producen una serie de actuaciones que conducen a la identificación de la edición y variante, que requieren procesos de investigación por parte del bibliotecario (distintos de la propia catalogación), apoyado por las herramientas identificativas existentes. Pero una vez determinada la edición y variante, es preciso establecer como sería el ejemplar ideal de la edición concretada. Desde la perspectiva textual y bibliotecaria existe el concepto de ejemplar ideal: aquél que más se aproxima a la intención del autor, editor o impresor. Se busca con este ejemplar ideal elaborar la descripción, al margen de las características individualizadoras del ejemplar.

Un mayor conocimiento de la obra, de la edición o del ejemplar aporta un valor añadido a la obra, a la edición o al ejemplar. En el proceso de tratamiento se produce un primer momento de valoración.

Valoración no es lo mismo que tasación: la valoración está relacionada con la investigación. La investigación sobre el fondo también produce valor añadido. El fondo (colección) tiene un valor que supera al del conjunto de unidades. La materia (tema) de una unidad no tiene interés para la biblioteca, sino la adecuación a la colección. Pero no es menos importante el estudio del conjunto, del fondo antiguo: estructura, composición, procedencia, evolución, cronología..., ya que se trata de analizar una serie de aspectos de gran interés para la investigación.

\section{La potenciación de la investigación y la difusión como elementos de valoración del fondo}

La investigación revierte en la biblioteca proporcionando un mayor conocimiento de las unidades y del fondo. Este es el fundamento principal que potencia la valoración de los fondos, también en todos los aspectos relacionados. Para poner en valor estos fondos y colecciones es, por consiguiente, necesaria su difusión, disponerlos para que los posibles usuarios los conozcan. La puesta en valor de los fondos mediante la difusión de los contenidos y de sus circunstancias es la segunda de las vías que se analizan.

El libro comporta por sí mismo, como se ha visto, valores diversos que, en muchas ocasiones, son más o menos evidentes o, en cualquier caso, identificables con las herramientas de identificación con facilidad: la primera impresión de un lugar o una nación, la presencia de ilustraciones, los contenidos de una primera edición... Una somera investigación apoyada en las herramientas de identificación apropiadas proporciona la información suficiente, pero en ocasiones es precisa una investigación más profunda que proporciona también información de mayor relevancia.

La biblioteca ante esta situación puede tomar dos opciones diferentes. En la primera de ellas la biblioteca puede servir de lugar de consulta del ejemplar poniendo en relación al usuario con 
su ejemplar, esto es la aplicación de las leyes segunda y tercera de Ranganthan, se trata de una opción estática. Una segunda opción es aquella en la que la biblioteca además promueve acciones específicas que pretenden dar a conocer de la forma más profunda y precisa las unidades que componen los fondos bibliográficos que custodia y, además, las individualidades que lo componen; es una opción dinámica.

No se pueden olvidar los sistemas clásicos de la difusión para la recuperación. La publicación de los catálogos de las colecciones es capital para la puesta en valor de los fondos. Especial mención hay que hacer a los sistemas de reproducción para la consulta e investigación y las dificultades que puede ocasionar una mala política de reproducción. Se tratan también otros métodos de difusión, entre los que merece especial mención a la confección de facsímiles y a las exposiciones, sin que puedan omitirse la utilización de las tecnologías y la virtualidad.

La biblioteca puede poner en este caso algunos medios para la valoración de sus fondos bibliográficos: servicios muy completos de información bibliográfica, potenciación del préstamo (incluido el interbibliotecario), potenciación de servicios eficaces de reproducción de documentos, desarrollo de servicios de difusión especialmente dedicados a la confección de facsímiles y la preparación de exposiciones. Además de la difusión de los catálogos por procedimientos tradicionales, impresos, opacs, accesibles desde Internet...

La biblioteca de referencia debe contar, al menos, con repertorios bibliográficos, diccionarios y otras obras de referencia sobre fondo antiguo, en papel y en otros soportes, monografías y estudios sobre historia del libro, la imprenta y las bibliotecas, catálogos de otras bibliotecas con fondo antiguo en los distintos soportes, puestos con conexión a Internet. Esta biblioteca debe servir de apoyo al investigador que consulta las obras, pero sobre todo al propio personal de la biblioteca en las actividades de identificación, descripción y catalogación.

Es interesante potenciar el préstamo de cara a que los investigadores tengan las máximas facilidades para estudiar tanto los fondos como los documentos individuales de la biblioteca. Esto es, aplicar la primera ley de Ranganthan: "Los libros son para usarse." El servicio de préstamo interbibliotecario en el fondo antiguo no presta, lógicamente, la obra, sino su reproducción. Las principales bibliotecas cuentan con este servicio, que gestiona el préstamo en cualquier otro centro, aunque el resultado depende de la bi- blioteca que tenga la obra que se pretende reproducir.

Es preciso que funcione bien un sistema de reproducción de documentos. Se ha de rechazar la utilización de la fotocopia en fondos antiguos que se ven muy afectados por la exposición a la luz. Se ha de ofrecer un servicio fotográfico que proporcione fotografías y diapositivas a los investigadores. Siempre es preferible que este servicio sea aportado por la biblioteca y realizado por profesionales que conozcan a la perfección los procedimientos que no afecten al documento. Es un servicio muy desigual, pues solo las grandes bibliotecas cuentan con laboratorio fotográfico, por lo que la mayoría depende de servicios externos, lo que puede retrasar y encarecer el servicio. La digitalización permite que copias del documento puedan llegar a los investigadores mediante petición por correo o mediante acceso en remoto a través de Internet. Algo similar ocurre con el microfilm que ofrece la posibilidad de solicitarse por correo y que puede servir de base para la realización de digitalizaciones. Todos estos métodos ofrecen la ventaja evidente para el investigador de permitir la consulta del documento sin tener que acudir personalmente a la biblioteca, favoreciendo la comparación cualitativa entre ejemplares y el ahorro de tiempo para el usuario - cuarta ley de Ranganathan, "Debe ahorrarse el tiempo del usuario"-; pero también presenta algún inconveniente importante para la investigación, como el hecho de que no ofrecen una reproducción exacta en cuanto al tamaño del original, lo que dificulta establecer comparaciones cuantitativas entre ejemplares.

Casos especiales son la elaboración de facsímiles de las obras de la biblioteca. Los facsímiles son un medio excelente para la preservación y divulgación. Esta actividad puede ser originada por investigadores que desarrollan investigaciones sobre determinadas obras o ediciones o puede ser originada por la biblioteca con motivo de eventos especiales, celebraciones... En el primero de los casos resulta conveniente suscribir un contrato o convenio en el que constarán los títulos de las obras y la finalidad del contrato, además ciertas "condiciones mínimas". En uno y en otro caso, se obtienen reproducciones que deben ser lo más fieles posibles con el original. El interés y el beneficio de una determinada empresa debe derivar en una contraprestación en beneficio de los ciudadanos, como es el de "la máxima y correcta difusión del original a través de su reproducción facsímil". Se considera que es un medio eficaz para facilitar el acceso y evitar, a su vez, los daños. Puesto que no se puede olvidar que las bibliotecas están 
obligadas a facilitar el acceso a los libros y documentos que constituyen sus colecciones, con las restricciones pertinentes. Estas reproducciones se rigen por un conjunto de reglas que fueron dictadas por el Grupo de Patrimonio Bibliográfico en 2000 y publicadas en 2002. En el contrato entre la biblioteca debe figurar la mención exacta de la obra, incluida la signatura topográfica y la parte que se reproduce, si es parcial, el plazo máximo de validez del contrato o convenio, y la fecha de entrada en vigor del contrato o convenio. Cuando se produce una coedición entre el que lo solicita y la biblioteca debe figurar el reconocimiento de ambas partes como titulares del "copyright" de la edición, debiendo figurar la mención y logotipo de la biblioteca en lugar destacado de la portada y ésta supervisará la totalidad de la edición; los gastos de estudio, por esta causa, trascripción, traducción, producción, distribución y difusión correrán a cargo del editor que solicitó la edición incluso en caso de coediciones. En el caso de editores que realizan un facsímil, se indicará el compromiso de la biblioteca de facilitar al editor el acceso al original $y$, del editor, de dar a la edición la máxima difusión posible, así como la validez de la autorización para una sola edición sin exclusividad. El editor se compromete a no utilizar la reproducción para una reedición o para otra publicación sin autorización expresa escrita de la biblioteca. La procedencia del original figurará en lugar destacado. Además, se estipulan una serie de cláusulas para el cuidado del original: la biblioteca tiene derecho a controlar el proceso de manipulación y reproducción del original, a supervisar la reproducción obtenida para garantizar su calidad y fidelidad al original. El editor, por su parte, se compromete a suscribir una póliza de seguro, aprobada por la biblioteca, para prevenir daños, a entregar a la biblioteca la copia original de la reproducción y a entregar a la biblioteca el número de ejemplares de la edición facsímil que se acuerde. En este contrato se incluyen también las cláusulas de resolución del contrato o convenio y la forma de resolución de las controversias mencionando la jurisdicción competente y, en un anexo, las características técnicas, la tirada de la edición y el precio de venta al público.

Mucho más centradas en la difusión son las exposiciones. Las bibliotecas con fondos antiguos, especialmente las que se denominan bibliotecas históricas, han encontrado en las exposiciones una herramienta de difusión de sus colecciones de primera magnitud. Se efectúan exposiciones virtuales y reales, temporales y fijas, especializadas y generales. El desarrollo de las mismas ha puesto de manifiesto que el usuario descubre el libro que precisa porque se le muestra integrado dentro de un conjunto armónico y organizado.

Las bibliotecas a la hora de realizar una exposición deben considerar el grado de afección de la posición y exposición del documento al público. Es el principal medio para la difusión del conocimiento del patrimonio bibliográfico entre una amplia población. En las exposiciones se pretende dar a conocer los fondos conservados en las bibliotecas, su valor como transmisores de una cultura centenaria, la importancia de su buena custodia y, en definitiva, promover la conciencia social del valor de los fondos conservados en las bibliotecas como bienes culturales y testimonios fundamentales para el conocimiento de la historia de las ideas y de la expresión literaria de los pueblos. Hay dos tipos de actividades de difusión básicas; las exposiciones monográficas, cuyo objeto es mostrar los libros más destacados de una colección en un conjunto orgánico que facilite el conocimiento de los fondos y el desarrollo de las ideas; y las muestras permanentes sobre la historia del libro, que se reflejan en los "museos del libro", en los que los libros se exhiben para mostrar el desarrollo de la cultura escrita desde una perspectiva fundamentalmente material.

Se precisan unas garantías para que, en el caso de las exposiciones monográficas, este fin no perjudique la integridad de los fondos. El Grupo de Patrimonio Bibliográfico redactó la propuesta de unas directrices, que se aprobaron en 1999, y fueron publicadas en 2002. Establecen el plazo mínimo para cursar la petición de préstamo, que se fija entre 3 a 6 meses antes de la exposición. En este plazo se podría proceder a una posible restauración, microfilmación, fotografía y montaje de la obra, ya que antes de proceder al préstamo, las obras deben ser microfilmadas o reproducidas, los gastos pagados por la organización y las copias deben quedar en poder de la biblioteca. Si es preciso también se procederá a la restauración de la obra, cuyos gastos correrán a cargo de la organización; por último, el montaje se hará según el criterio de la biblioteca. No obstante, se puede denegar el préstamo por motivos de conservación o científicos. La solicitud de préstamo se debe acompañar de un informe en que se detalle el objeto y contenido de la exposición, especificando una serie de datos relacionados con el conjunto de obras, fechas, condiciones ambientales y de seguridad de la sala, etc. La organización deberá garantizar la seguridad y conservación de los materiales expuestos. La biblioteca tiene derecho a inspeccionar dichas medidas. Por esta causa, todas las obras deberán estar aseguradas mediante una póliza "puerta a puerta" que cubrirá 
todo el tiempo que esté fuera. La biblioteca fijará el valor de cada obra, que estará incluido en la Orden Ministerial o legislación correspondiente. La biblioteca tiene el derecho de rechazar la compañía propuesta por la organización de la exposición. Ésta, además, deberá entregar el certificado de seguro a la biblioteca antes de recibir las obras. Las obras se retirarán mediante la firma de un acta de entrega y su traslado se realizará por una empresa especializada en el transporte de obras de arte. La biblioteca tiene derecho a rechazar la empresa propuesta por los organizadores. Las obras irán debidamente embaladas en condiciones adecuadas de humedad, temperatura y golpes. Cuando la biblioteca lo considere conveniente enviará, junto con las piezas, una persona que supervise el transporte y la instalación. El préstamo se hará para una sola exposición. Solo se considerará el carácter itinerante si existiera un período de reposo de dos meses en la biblioteca, no pudiendo el préstamo superar los seis meses al año. Agotado este período, las obras no podrán ser prestadas en los próximos cuatro años. La exportación temporal a exposiciones en el extranjero será aprobada por la Comunidad Autónoma y por la Junta de Calificación, Valoración y Exportación de Bienes del Patrimonio Histórico Español. La organización será responsable de los trámites aduaneros. Acompañará a las exposiciones la edición del correspondiente catálogo que - con la reproducción de los fondos y con estudios pormenorizados de cada pieza, a los que pueden complementar estudios parciales por especialistas- se convierten en obras de difusión y de consulta. A veces, incluso, son auténticos instrumentos de localización y de identificación, de más valor cuanta mayor información contengan. No se permitirá la reproducción total o parcial de las obras excepto para el catálogo de la exposición, previa solicitud y permiso por la biblioteca. Se deberán entregar 5 ejemplares del catálogo a la biblioteca. Se deberá mencionar la colaboración de la biblioteca en todas las comunicaciones públicas, y en el catálogo. Concluida la exposición se procederá a la devolución, dejando un plazo para el desmontaje y transporte que no supere el incluido en la Orden Ministerial si es de propiedad estatal. Si hubiera alguna incidencia se incluirá una nota en el acta de devolución, por si se exigieran responsabilidades. En caso de litigio, ambas partes se someterán a la jurisdicción de los tribunales del territorio de la biblioteca.

Son también métodos de difusión muy desarrollados en las bibliotecas las visitas organizadas, especialmente de bibliotecarios o especialistas en formación; aunque sólo son aceptadas por los Centros más importantes, que pueden deri- var personal para este fin, las publicaciones sobre la historia y los fondos de la biblioteca, las convocatorias de premios de Investigación sobre los fondos y las conferencias y otras actividades culturales en sus instalaciones. De esta manera, la biblioteca (con fondos históricos) se transforma de un cadáver bibliográfico en un organismo vivo, cumpliendo con la quinta regla de Ranganathan: "La biblioteca es un organismo que crece." En, este caso, en valor.

\section{Los valores del libro antiguo en la biblioteca}

Resulta interesante establecer que hace especiales a los fondos antiguos. Estos fondos poseen una serie de valores generales que los hacen distintos a los demás. Entre los valores aplicables podrían diferenciarse los que, siguiendo a Tugores y Planas (2006), se enumeran a continuación.

El primero de ellos sería el valor subjetivo, en tanto en cuanto se trata de un valor relacionado con el concepto de cultura que, como resulta evidente, es un concepto complejo sujeto a tantas interpretaciones como analistas se interesen por él. Una carta puebla tiene distinto valor para la sociedad que la genera que para otras de su entorno. Algo similar ocurre con las primeras producciones tipográficas de una comunidad, para quien posee un valor especial. Cada documento tiene una ubicación apropiada en la que su valor alcanza su máximo nivel.

El valor pedagógico sería otro de los trascendentes. Los libros antiguos son transmisores de conocimiento puesto que son elementos transmisores entre generaciones de la memoria histórica y de los conocimientos del pasado. El valor pedagógico se materializa en la transmisión de las experiencias pasadas y conocimientos que se generaron en el pasado y que son usados en el presente. Las sociedades que desconocen el pasado están condenadas a repetirlo. El documento escondido u ocultado no cumple su función.

El legado que recibe un pueblo con el transcurso del tiempo es tan grande que no puede ser conservado en su totalidad, lo anterior es sustituido por lo posterior; sólo se ha conservado una selección, el resultado de elecciones sucesivas. El libro conservado tiene un valor selectivo. Es preciso incidir en que el valor de los libros que conforman un fondo es también el de los elementos destruidos o excluidos intencionadamente o por no haber merecido la consideración de ser conservados. Los libros y bibliotecas desaparecidos hablan de las sociedades 
que los destruyeron. Un documento que pervive es trascendente por su mera supervivencia.

Los libros antiguos, los fondos antiguos, poseen un valor ideológico. La ideología que impregna todo, incluso la cultura, será una de las principales causas de destrucción o conservación. También en ocasiones de su manipulación. El documento en si mismo trasciende su contenido

Se puede encontrar también un valor de consenso. En tanto en cuanto la sociedad genera nuevos documentos, éstos, debido a la imposibilidad de su conservación íntegra, deben de ser seleccionados mediante una serie de criterios consensuados. Algunas de las producciones actuales son conservadas fruto del reconocimiento común y del consenso, ya que no existen límites cronológicos en la delimitación del objeto patrimonial. El documento que pervive normalmente fue seleccionado para ello.

Tan importante como el factor de la conservación del PBD es el de su investigación. La investigación aporta también un valor de progreso produciendo nuevo conocimiento que conduce al progreso científico. Un documento tiene sentido si se investiga y consulta.

La documentación en general posee siempre un valor estético, ya que es el resultado del gusto de una época. No siempre es muy evidente este valor pero un documento responde siempre a unos gustos, bien sea por un tipo de letra, por una distribución de la páginas, por unos adornos concretos... Hay que tener en cuenta la materialidad, ilustración, tipografía, encuadernación... El documento posee siempre información estructural, en ocasiones de interés estético.

El valor histórico es un valor consustancial al de libro antiguo. Estos documentos forman parte del patrimonio, que es la salvaguarda del valor histórico del bien. Puede tener una doble vertiente: el valor histórico como objeto en si mismo o su valor histórico en función de su procedencia. Un documento adquiere su sentido en su contexto histórico

Los fondos antiguos tienen un componente rememorativo, un valor identitario, son aquellos que resultan más adecuados para recordar los momentos históricos más destacados, aunque no sean útiles para la historia. El documento identifica a los contemporáneos.

El alcance del concepto de fondo antiguo es integrador, ya que abarca no solo a los componentes individuales sino también, en muchas ocasiones, a su entorno y, en ocasiones, a objetos de muy diversa naturaleza. Cuando se trata de un libro que se encuentra imbricado en un entorno, en un fondo, desde esta perspectiva adquiere un valor integrador. Un documento se entiende mejor en su entorno y a la inversa.

También se encuentra un valor universal. El interés de los fondos antiguos no es particular; es general independientemente del territorio en que esté ubicado y de quién ostente su titularidad.

Es evidente que los fondos antiguos poseen un valor testimonial. Forman parte del tesoro común de un pueblo que integra lo que a ese pueblo le ha interesado y lo que ha producido intelectualmente; también, lo que los antecesores consideraron de suficiente importancia como para plasmarlo en libro o documento. La información de cualquier documento ha tenido siempre trascendencia.

Por último, los fondos antiguos poseen un valor económico y su perdida implica siempre un empobrecimiento de la sociedad que los generó. La existencia de un valor económico facilita su gestión puesto que permite la comparación. El valor económico es el único que puede poner en relación objetos heterogéneos. Los documentos aportan riqueza a la sociedad.

Ninguno de estos valores resulta evidente por sí mismo. Tras la puesta en valor de los documentos integrantes de un fondo bibliográfico antiguo, hay un proceso de trabajo por parte de los bibliotecarios para ponerlo en valor y por parte de los investigadores, que aportan nuevas informaciones relevantes sobre el mismo, que establecen valores nuevos de los documentos y de los fondos en los que se integran.

\section{Referencias}

Carrión, Manuel (1987). Manual de bibliotecas, Madrid Pirámide: Fundación Germán Sánchez Ruipérez, 1987.

Congreso Internacional de Historia de la Cultura Escrita $\left(7^{\circ}\right.$. 2004. Alcalá de Henares) (2004). Conservación, reproducción y edición: modelos y perspectivas de futuro: VII Congreso Internacional de Historia de la Cultura Escrita. Guadalajara: AACHE Ediciones de Guadalajara, 2004.

Clavería, Carlos (2002). Criterios objetivos y subjetivos de tasación: continental books y miseria // Pedraza Gracia, Manuel José (ed.). Tasación, valoración y comercio del libro antiguo (textos y materiales): Jaca, 2-6 de septiembre de 2002, Zaragoza: Prensas Universitarias de Zaragoza, 2002. 167-181.

Dexeus Mallol, Mercedes (2001), Las instituciones públicas ante la oferta de libros y documentos de interés histórico // Symposium de Archivos Familiares (2 ${ }^{\circ}$ 2000. Escalante), Tasación y valoración de archivos. Santander: Asociación para la Defensa del Patrimonio Bibliográfico y Documental de Cantabria, 2001. 13-34.

García, Idalia (2002). Legislación sobre bienes culturales muebles: protección del libro antiguo. México: CUIB: BUAP, 2002

Herrera Morillas, José Luis (2004). Tratamiento y difusión digital del libro antiguo: directrices metodológicas y guía de recursos. Gijón: Trea, D.L. 2004. 
Marsá, María (1999). El fondo antiguo en la biblioteca. Gijón: Trea, 1999.

Martín Abad, Julián (2004). La valoración del libro: el punto de vista del bibliotecario de fondo antiguo // Ciclo de Conferencias sobre Bibliofilia y Mercado del Libro. Madrid: Biblioteca Histórica Marques de Valdecilla, 2004. http://www.ucm.es/BUCM/foa/documentos trabajo.htm (2008-05-07)

Normas de préstamo de obras de la biblioteca para exposiciones (2002). Madrid: Ministerio de Cultura, 2002.

Oddos, Jean-Paul (1997). Le patrimoine : histoire, pratiques et perspectives. Paris: Electre-Éditions du Cercle de la Librairie, 1997.

Pautas para la autorización de la reproducción y edición facsímil de las obras conservadas en bibliotecas públicas (2002). Madrid: Ministerio de Cultura, 2002.

Pedraza Gracia, Manuel José; Yolanda Clemente San Román; Fermín de los Reyes Gómez. (2003). El libro antiguo. Madrid: Síntesis, 2003.

Tugores, Francesca y Rosa Planas (2006). Introducción al patrimonio cultural. Gijón: Trea, 2006.

Varlamoff, Marie-Thérèse (dir.) (1999), Estudio IFLA/UNESCO sobre digitalización y conservación (compilado y revisado por Sara Gould y Richard Ebdon). Wetherby: IFLA Offices for UAP and International Lending, 199 